\title{
Entrevista com Tânia Cordeiro
}

\begin{abstract}
Resumo: A professora Tania Regina Fernandes Cordeiro é graduada em Comunicação Social pela Universidade Federal da Bahia (UFBA) e mestre em Comunicação pela Universidade de Brasília (UNB). E coordenadora de comunicação do Fórum Comunitário de Combate à Violência e professora adjunta da Universidade do Estado da Bahia (UNEB). Seu campo de atuação e pesquisa dialoga com temas relacionados à comunicação comunitária, com especial atenção aos enfoques sobre mídia, violência, cidadania e juventude. Atualmente tem se dedicado à investigação sobre o Facebook e suas implicações no campo da comunicação política. Conduziram as perguntas os professores Maria do Socorro Carvalho e Rodrigo Maurício Freire Soares, e a mestranda Qhele Jemima Pinheiro de Melo Barros. A transcrição foi realizada pela estudante de graduação Vanessa Rosendo de Souza.
\end{abstract}

\section{Pergunta (P): Como pensar a comunicação no momento em que vivemos hoje (agora?) no Brasil?}

Tania Cordeiro (TC): O momento de agora está comprometido com várias perguntas que a gente nunca se fez, e, por exemplo, estamos vivendo uma situação muito extraordinária na política, na economia e uma situação de comunicação muito extraordinária. Mais do que nunca, com maneira muito óbvia, se coloca a comunicação como uma coisa muito importante dentro de uma circunstância política que é, infelizmente, um golpe de estado, e nesse golpe de estado a comunicação aparece como um dos fatores determinantes. Ele todo é moldado em novas condições daquelas que se tinha antes relativamente ao próprio conceito de golpe de estado. Antes não havia motivo para pensarmos no valor que a comunicação tem no golpe de estado, mas agora, por exemplo, a comunicação passa a ter, e se 'passa a ter, torna-se uma obrigação nossa nos perguntar: "Que comunicação é essa?", mas com um a nudez de quem não sabe mesmo. Porque o que tem acontecido é que se tá dando por descontado que sabemos de tudo. Basta dizer "a mídia..." e tudo está esclarecido. Nós não sabemos de nada! É preciso fazer essa pergunta que permaneceu oculta em outros tempos, em situações análogas, porque agora nós temos as condições para fazê-las, e esse é um aspecto que domina a minha preocupação atual.

É preciso levar em consideração que nós estamos diante de um mistério e tal mistério é que faculta e dá poder pra gente fazer perguntas. O nosso agora nos remete, nos impõe a condição de produzir de novo dúvida e não ficarmos ancorados em certezas padronizadas já bastante estabelecidas. Nesse sentido, a gente tem muito a necessidade de, novamente, dar lugar à dúvida como sendo ele o lugar mais privilegiado na ciência, na atuação de uma pessoa que faz pesquisa. Questionar sobre o que é duvidar, mas também sobre o que é dirimir a dúvida, e então dirimir dúvida cria uma espécie de alívio para além daquilo que a própria pesquisa oferece, mas tem-se um contexto social que se aquele problema está bem posto nesse contexto, esse fato de você alcançar a condição de dirimir certas dúvidas, sendo elas importantes socialmente, a própria ciência ganha - isso é importante, Bourdieu fala muito disso, o capital científico advém também daí - mas cria também uma impressão para a população de um modo 
geral, de que a ciência uma vez dirimida dúvida não temos mais nada, é alguma coisa que não tem mais futuro.

Manter a dúvida e ter a condição de fazer dela a sua energia é muito mais importante do que ter a resposta e ficar petrificado nessa resposta, coisa que Bachelard muito claramente critica. E no caso específico que é o golpe, que aqui é um elemento para ilustrar, é uma cena perigosíssima porque todas as pessoas hoje falam "É a mídia", mas eu não estou vendo tantas pessoas explicarem propriamente qual é o papel da mídia. Eu tenho bastante - não vou usar a palavra convicção, que não é conveniente para o contexto - mas estou convencida e tenho uma hipótese muito forte de que, de fato, a mídia está desempenhando um papel extremamente ativo e fundamental para o sucesso desse golpe. Mas, daí a ficar simplesmente gritando o que a mídia 'está fazendo', não resolve.

Nós estamos vivendo uma situação de educação: as pessoas não sabem o que é um golpe, as pessoas - de um modo geral - não conhecem as coisas que estão perdendo, como por exemplo, os seus direitos, ou o que significa realmente uma Petrobras e etc., e, no entanto, você chega pra ela todos os dias e repete "a mídia; a mídia; a mídia...". É preciso dizer um pouco mais sobre o que é isto. Então esse "o que é isto" é um agora onde isto - essa tal mídia, esse tal objeto - está tendo um papel que ela não poderia ter tido exatamente o mesmo papel no golpe de 64, por exemplo. Nós estamos ouvindo dizer que esse é um golpe diferente, e se ele é diferente vão dizer que coisa é essa. É estranho porque as pessoas, e não apenas a mídia, mas as instituições como a Justiça, a Presidência da República, o Congresso, essas figuras elas estão fazendo tramas que eu tenho me convencido que praticamente estão sendo tratados como uma "coisa de novela". Portanto essa despreocupação, essa facilidade com que se diz que "é um golpe com essas características", me parece que elas são muito superficiais diante do que de fato está acontecendo.

\section{P: E como você vê as conexões entre as mídias sociais e a mídia tradicional? Como se pode tratar as conexões entre as mídias sociais e a mídia tradicional?}

Pensando nas comparações de um contexto em que se tem a presença marcante das mídias sociais, mas também de equipamentos capazes de produzir as condições para que essas mídias tenham peso e tenham certo valor na sociedade. Portanto, a gente não pode - na análise que se faz - deixar de lado a especulação sobre essas mídias também. Elas estão a produzir o que eu tenho achado como um poder para os meios de comunicação tradicionais, porque essas mídias acordam e dormem falando mal deles. E o uso é um uso apaixonado, é um uso extremamente cheio de emoções e isto está principalmente dizendo o quanto essa mídia tradicional é importante. Assim, o próprio fato de tanto se dizer sobre ela, dá a essa mídia tradicional um lugar mesmo dentro da própria mídia não tradicional. Então há uma preocupação excessiva em dar a esse aspecto uma prevalência, uma notoriedade, quando faz parte do poder da mídia ela existir pelo outro, existir pelo que o outro está dizendo, e aí você dá ao seu, "entre aspas", inimigo todo o poder, você que está conferindo, logicamente não é você sozinho, a própria mídia estaria tendo desempenho importante, mas, não tenha dúvida: você todo dia está usando seu tempo e dos outros, que são seus receptores, para dizer "Olha, são eles que estão atrapalhando". E são coisas 
desse tipo que, me parecem, tornam necessárias que a gente faça a pergunta "E agora? O que é isso? Como é que a gente pode observar isso?".

Tem coisas que não dá para brincar! Por exemplo, a mídia está sendo muito redundante, esta tal "midiazona", e a redundância é uma necessidade para que ela seja vista hoje, amanhã e depois, e você tá vendo na redundância o que ela quer. A mídia não tem tratado do que é o direito que se perde, ela simplesmente diz que acabou. Acho muito interessante que as mídias sociais tomassem pra si a condição de provocar aos receptores dizendo "O que é isso mesmo que acabou?", e "como construir essa resposta sobre o que acabou". Dizer coisas sobre o que significa, por exemplo, a lei trabalhista, me parece dizer "É isso que está acabando". Deixar de lado como quem não tivesse escutado o que a "midiazona" disse porque a gente está dizendo que ela não está informando - a gente passa a informar sobre as coisas que estão sendo perdidas.

Tem coisas que precisam ser feitas, a exemplo de direitos que nunca foram percebidos, mas agora tem mais chance de se mostrar. Então por que você ao invés de dar essa "colher de chá" não se aprofunda nessa sensação de perda, nessa falta que as pessoas passam a ter, nessa insegurança?

\section{P: Como você analisa, no contexto atual de múltiplas mídias, o processo de circulação informações?}

Eu acho que, na situação que estamos, não existe uma coisa ideal para "onde colocar a informação", então é nas coisas e nos espaços que você consegue alcançar, não tem outro jeito! Porque nós não estamos com capacidade de dizermos "falta a nós buscarmos isso...". Não, não é por aí. A gente tem de olhar para as possibilidades que temos e o uso que a gente está fazendo com as tais possibilidades. Por exemplo, eu me levei a pensar: afinal de contas o Facebook, que tanto está sendo usado, eu vou tentar observar o que é que está acontecendo ali. E assim, uma das coisas que eu pude observar é que todos nós somos ali convertidos, e você não suportaria não ser convertido. Mas, você tem que oferecer nessa conversão um pouco mais do que amém, você precisa trocar, você precisa propor coisas, precisa colocar pra circular nesse espaço coisas que não estão circulando. E também reconhecer coisas que estão novas que estão circulando e que são interessantes de se colocar. Essas coisas infelizmente são poucas, mas essas aí estão tendo um uso regular do jeito que há um uso regular das grandes mídias. É desproporcional? Totalmente desproporcional, mas também a gente não pode agora aguardar uma espécie de justiça, de uma equidade, numa coisa que é o golpe. Então, que coisas poucas se pode fazer? Porque essas coisas são parte das contradições que se tem hoje e que eles não podem controlar.

P: Vivemos um momento em que o "lugar de fala" é um tema evocado com certa frequência, uma vez que há maior clareza da importância de que múltiplas vozes tenham espaço na sociedade contemporânea. Contudo, neste contexto, que peso estamos dando ou não à escuta? Como ficam os "lugares de escuta"? 
$\mathrm{Na}$ verdade esses lugares de escuta eu chamaria hoje de troca. Nós estamos vivendo muito individualmente um problema que é geral. Nós estamos cada um no seu lacre, e isso tem impedido a geração daquilo que poderia ser escutas mais ricas. O que tem acontecido de uma maneira mais básica é que as situações de escuta elas têm sido promovidas aos trancos e barrancos nos grandes eventos, sendo situados como suposição de que vão dar conta de tudo. Um grande evento praticamente está virando quase um deus, e isso acaba por deixar de se usar, de se pensar em coisas mais modestas, mas capazes de trocas mais consistentes, e nesse sentido - e aí eu volto para o meu agora - é que a gente está numa situação de luta que é mais ou menos assim: as coisas têm que ser quase que ao mesmo tempo, e tenho a impressão de que as pessoas estão deixando para um depois uma coisa que o agora exige que é justamente essa capacidade que a gente deve ter de escuta.

\section{P: Parece haver um elemento que se destaca nesse nosso agora: o campo jurídico. Que papel deve ter a comunicação para lidar com ele, sempre visto como um poder distante do mundo das "pessoas comuns"?}

Imaginar que uma sociedade que saiu de uma baita de uma ditadura tem uma constituição badaladíssima, uma carta cidadã, e quando chega nessa hora ninguém sabe o que é essa constituição. Observe o quanto temos de distância desse negócio que era mágico, que ninguém sabia o que era! Então, desse não saber quanta escuta poderíamos ter tido, quanta possibilidade de se interessar pelo tema foi deixada de lado, e por quê? Porque todo mundo disse "Ah! As coisas estão funcionando". No mesmo tempo que nasceu essa nossa Constituição, é mais ou menos o período também em que todo mundo começa a se interessar pela informática e etc., tem-se certa proximidade temporal. Pois veja: Todo mundo hoje sabe mexer em tudo quanto é tecnologia digital, ou seja, houve uma dedicação a um determinado tipo de saber, que também é novo, e as pessoas se dotaram de interesses. Logicamente são temas muitos distantes, mas aqui a gente pode ter ideia do tempo do qual falamos. Então, a Constituição, em geral, é vista como uma coisa realmente de outro, e esse outro é o juiz, esse outro é o cara que não sabe falar com a gente. Nesse ponto eu acho que vale a pena que vocês se interessem pelo que Bourdieu também escreveu sobre campo jurídico, porque ele faz ver o quanto é um campo de difícil penetração e uma das coisas é a própria linguagem. Observa-se que eles criam todas as condições para evitar e assim eles sabem muito usar pela linguagem a "evitação". São extremamente hábeis nesse sentido. E, mais do que isso, essa espécie de lugar secreto não interessa às pessoas, então temos muita distância, e mais, nós pensamos que a coisa está muito difícil. É como um conjunto de mistérios, porque ninguém nunca vê que essas coisas parecem essas seitas satânicas, no sentido de tem que ficar dentro de um mistério, quando na realidade é uma coisa pública.

Vejam como está escrito na CF 1988: "Constituição da República Federativa do Brasil de 1988. Preâmbulo. Nós, representantes do povo brasileiro, reunidos em Assembleia Nacional Constituinte para instituir o estado democrático destinado a assegurar o exercício dos direitos sociais e individuais, a liberdade, a segurança, o bem estar, o desenvolvimento, a igualdade e a justiça como valores supremos de uma sociedade fraterna, pluralista e sem preconceitos, fundada na harmonia social e comprometida, na 
ordem interna e internacional, com a solução pacífica das controvérsias, promulgamos, sob a proteção de Deus, a Constituição da República Federativa do Brasil".

Coloco logo que eles estão representando a todos nós, e nós temos justamente essa ideia de que ela é uma coisa dos doutos da área de direito, então, por exemplo, as pessoas pensam que para fazer um habeas corpus, precisa de um advogado. Mas não, eu posso fazer, você pode fazer, qualquer um de nós pode fazer.

\section{P: Mas como a mídia lida com essas questões, ou melhor, como ela atua junto aos seus diversos públicos?}

Nós conseguimos uma espécie de distância da Constituição que permitiu a existência de coisas completamente absurdas no nosso país entre as quais, eu costumo dizer, que existe uma espécie de justiça do Estado, e outra midiática. As pessoas têm muito mais condições, inclusive de fala, indo a um programa de televisão que se estrutura a partir de problemas sociais muito graves, e é ali que ela vai contar o seu problema. Quanto mais ela levar a crueldade, a maldade todas as coisas que a estão magoando, melhor! Porque do ponto de vista midiático tem uma espécie de retorno mais adequado ao meio, e essa mesma pessoa terá muita dificuldade de procurar a justiça do Estado. Por exemplo, eu perguntado a uma pessoa que cujo filho foi morto sobre como é que ela se sentia ao ir ao fórum para saber como estava o processo relativo à morte do filho dela, que foi morto por um policial. Ela me contava depois de uns quatro anos da morte a seguinte história: "Olha, tem uma pessoa lá que é muito humana.", "O que essa pessoa faz?", "Ele fica assim: a gente pergunta, ele fica na máquina, e depois ele fala: 'Olha, mas nunca podia ter acontecido'.". Ou seja, essa é a ideia de fórum que ela tem. E ela vai diversas vezes lá pra saber exatamente da mesma coisa, e é a mesma pessoa que vai dizer isso. Então, observe como nós passamos a ter nas agências de televisão um lugar mais adequado, já que lá as pessoas podem contar sua história. E há ainda mais outro aspecto: que elas não percebem que estão sendo transformadas em um produto da indústria cultural - estou usando novamente esse termo, porque agora eu acho que vale muito repensar as teses de tempos atrás. Então, elas simplesmente são gratuitas, é uma gratuidade, elas vão bater à porta, elas são escolhidas - depois de tantas pessoas que chegam batendo à porta vai se procurar o caso mais adequado porque ele vai dar uma resposta midiática mais interessante do ponto de vista comercial -, e elas serão insufladas, no sentido de tornar bastante espetacular sua presença ali. E nessa hora elas se sentem como que "a justiça sendo feita". O condutor do programa que vai dizer "olha, vou te dar uma carta para o Ministério Público.", como se o Ministério Público fosse um elemento anexo da televisão, daquela agência que não está relacionada em nada com a justiça.

Inclusive agora quando a gente está observando a utilização da justiça sobre grandes figuras é interessante uma tese que se coloca como se fosse uma coisa completamente inadequada, porém essa é a justiça que se tem em relação a essas pessoas quando elas são mais pobres.

\section{P: E como atua o jornalismo nesse complexo jogo midiático?}


Ainda não percebemos que vivemos uma complexidade que vai muito além da possibilidade de uma única verdade, e no caso da justiça, do jornalismo e da ciência, nós estamos reféns dessas verdades. O jornalismo tem uma série de condições para nos propor como sendo a realidade aquilo que ele traz, e isto significa que o que ele não traz não existe, e/ou têm uma existência completamente irrelevante, do ponto de vista social. Esse é um problema muito sério quando você tem um jornalismo - como é o caso do nosso - que além de nunca poder ser tão total em relação a todas as informações que se tem no mundo, mas, sobretudo, um jornalismo que não tem compromisso em garantir à sociedade uma capacidade de informação que the dê condições de, em estando neste mundo sobre qual estou informado, como é que eu devo estar? Ou o que é que eu escolho? Ao contrário, o jornalismo cada vez mais tende a dizer que o mundo é uma coisa só e é aquilo que ele está dizendo.

No caso específico da justiça, é de outra ordem porque a justiça, os seus quase "tutores", os "donos da justiça" eles fazem o possível para que ela não seja percebida. E é bem interessante você poder verificar que quando a justiça estava mais desligada e descomprometida com a mídia, ela era uma coisa que a gente tinha, pelo menos no nosso imaginário, tínhamos certo respeito maior. Quanto mais a justiça se apropriou e a mídia se apropriou dela - é uma dupla apropriação, ela faz isso do mesmo jeito que as pessoas que fazem os programas de televisão em relação aos pobres - então ela tende a ser um produto midiático, tende a ter que dar respostas para a opinião pública. Essas situações em que ela é a verdade e uma verdade muito importante para o sistema, mas ela hoje está conformada à uma necessidade - e eu não sei nem se é necessário mesmo, há que se perguntar - de adequar-se ao tempo de mídia, à ideia midiática (que é novelística, o mal, o bem etc.), essas coisas que estão sendo colocadas; ao fato de que estas coisas, por sua vez, distanciam os receptores daquilo que deveria ser a justiça. O Poder Legislativo, Executivo e Judiciário, estão no poder e eles reclamam o poder democrático.

Eles também estão - e isso em um grau de desgaste muito grande para eles - sendo conhecidos, estranhamente, estão sendo apresentados, como por exemplo, a situação do legislativo. Antes você pensava assim: deputado entende do Brasil minimamente, mas desde o primeiro momento em que eles começaram o julgamento de Dilma, todo mundo começou a descobrir que eles são pessoas completamente despreparadas para o cargo. É um cargo que vai dizer como é que as coisas vão funcionar. São eles que vão dizer, por exemplo, também o que não está correto em relação àquilo que estabelece a própria Constituição, é também importante para eles, não é só o judiciário que tem que pensar nisso. São pessoas que você percebe claramente que não sabem o que é cargo. Então, eles são apenas; não sabem o que são. E esse não saber dá pra eles outra forma de ser deputado que é justamente o "anti-deputado", o "anti-senador" que é o cargo pra si, "O cargo é meu, eu faço dele o que eu quero". Portanto, é como se a gente estivesse vivendo um jogo onde existem regras, mas se todos que jogam não conhecem as regras, não as defendem, então eles vivem o jogo muito mais criado por eles, e esse jogo criado por eles pode ser antagônico ao jogo formal que eles deveriam incorporar.

Quando se tem um cargo, você se encarrega de uma determinada missão, mas a ideia deles é que uma vez votado ele faz disso o que quer, e esse o que quer pode ser para o bem e para o mal, para qualquer lado. Então, chegamos a um ponto em que nós temos um conjunto de palavras que dão sentido extra, fora do próprio jogo. Nós temos um congresso, nós temos deputados, nós temos esses nomes, 
esses vocábulos que têm determinadas regras, mas é como se isso: "termos o discurso de que temos estas coisas" fosse suficiente, eles não precisam corresponder ao papel. Nós estamos realmente na situação atual sendo obrigados a sofrer - eu acho que o sofrimento inclusive é quase doentio mesmo, não é um sofrimento leve - que é observar que nós estamos pagando pra esse cara ser isso, então nós nos distanciamos bastante. Nesse sentido é um jogo que cabe a quem está descobrindo como é o jogador, o jogador simplesmente deixou o campo e foi pra outro jogo, e o campo está lá vazio, a ponto dele (o jogador) está já fazendo coisas como: "é verdade que eu tenho que deixar de fazer esta ou aquela coisa". Observe como fica longe do campo onde ele deveria estar jogando, é como se fossem desertores: eles recebem aquilo, mas eles não têm nenhuma relação. $O$ que resta digamos pra eles enquanto compromisso formal é votar. Eles não sabem em quem devem votar, é preciso ter um líder que vai dizer "Vota nisso, aperta esse botão". Nós estamos numa situação em que não há possibilidade de jogar o jogo limpo, inclusive as pessoas que querem jogar limpo teriam que fazer o jogo sem os outros. Essa imagem é muito presente nas coisas que a gente tem visto ultimamente. Quando, por exemplo, se um parlamentar agiu dentro do jogo os outros ficam meio que "curtindo com a cara". Nós chegamos ao ponto da inversão em que aquilo que deveria ser o jogo virou um pretexto pra existência dos cargos apenas. É mais ou menos isso: é como se você tivesse uma baita estrutura, mas ela é toda inutilizada porque as pessoas que deveriam utilizá-la não têm nenhuma condição.

\section{P: Como essas relações que podem ser feitas a partir do campo da comunicação ajudam à ideia de conhecimento do mundo?}

Vale a pena observar o que é mesmo ser perito, conhecer um pedaço, entender de uma situação, porque isso também é importante para o agora e como a gente vai poder ter lentes para observar. Nós somos dotados de experiências, de capacidades muito específicas. Nós não sabemos tudo, mesmo nas coisas que a gente estuda, é um infinito, então, por conta disso, eu acho há que se fazer uma reflexão a propósito dessa distinção entre esse saber que deve ser, digamos assim, melhor estabelecido, e nossos saberes comuns para a vida diária.

Nesse momento, me tomo como exemplo: há um tempo começou a acontecer comigo coisas no meu corpo que são, digamos assim, um pouco estranhas. Eu passei a ter muito cansaço, eu passei a ter muitas dores; tudo isso quando chegava a mim, eu colocava na conta da idade - eu estou com 59 anos. Eu era uma pessoa bem mais magra, digamos muito mais magra e de repente eu olhava no espelho minha cara tava grande: era a idade; e depois a barriga grande: era a idade; e eu ia fazer ginástica: era a idade. Então eu passei a ter algumas coisas: cair na rua, cair em casa. Houve uma coisa cômica: eu estava certa vez numa banheira, tomando banho, e não consegui sair da banheira, alguém teve que me pegar. Um dia eu fui ao meu médico cardiologista, ele fez todos aqueles exames e depois disse pra mim "Tânia, tem alguma coisa que eu vi em seu abdome que vale a pena você investigar" e me deu as indicações. Eu descobri que tinha uma doença; uma das coisas que se mostra com evidência nessa doença é justamente ter a "cara redonda". Depois tinha outra coisa que era o cansaço, não ter força, enfim, todas essas coisas que era toda essa minha velhice, foi disso que eu descobri a doença chamada 
síndrome de Cushing e, o impressionante é que eu nunca tinha ouvido falar, mas é também compreensível porque eu tenho, digamos assim, um "currículo" de registros de problemas de saúde, que é bastante rico, mas as doenças não são raras - é rico, é preocupante, etc., mas nenhuma grande raridade, mas essa em particular é uma doença em que a cada um milhão de pessoas somente três, é o que se diz, têm essa doença. Então eu passei a ser uma pessoa que não tinha referência para doenças, porque todas as pessoas não sabem dela. Observe o quanto um problema, do ponto de vista metodológico, está dentro de mim: o que é esse agora? E eu não tinha condição de fazer a pergunta, justamente porque eu não tinha as referências capazes de fazer a pergunta. Então eu podia morrer sem ser diagnosticada, pra se ter uma ideia. Quando eu fui a um especialista, ela me olhou, olhou na região dos ombros - que também fica com umas saliências -, testou algumas coisas relacionadas à força; e identificar todas essas coisas permitiu que ela fizesse o próximo passo que era fazer vários exames, e eu fiz vários exames em São Paulo, e ela diagnosticou que eu estava com essa síndrome de Cushing.

É um bom um momento para se mostrar o quanto conhecer não é propriamente estar ali agarrado, fazendo parte, ao contrário, é você ter a condição de se perguntar o que é, e aventar que aquilo é alguma coisa que foge a essa minha resposta que era a que eu tinha para me dar, que eu estava ficando gorda. Então, o perito, quem pensa a partir de parâmetros científicos, quem usa determinados métodos, tem mais condição de reconhecer, em alguma circunstância, um problema que a gente chama de problema científico, ou problema de pesquisa, e para isto esta pessoa ela precisa ter incorporado em sua vida um conjunto de saberes capazes de fazer essa tradução. É como se você olhasse para uma língua e não soubesse nada, então você pode passar cem anos olhando aquela língua. E nesse sentido, têm várias coisas que essa doença me faz pensar, por exemplo, essa história de eu não ter mais gente "Ô fulano, como é...? E a sua, como vai?" não tem não existe isso! E eu descubro o quanto se torna por esse próprio problema uma dificuldade de eu colocar alguma coisa relacionada ao tema, porque não há nas pessoas nada que se encaixe. Fica uma dificuldade dado o fato de que você tem um volume baixíssimo de pessoas que têm controle sobre isto.

Então você pode pensar assim como uma doença, você para pra pensar, por exemplo, quem é que tem o controle do saber sobre um Judiciário, o controle do saber sobre o nióbio - tem um nióbio aqui, mas para que serve? - então você tem isso e pode jogar fora porque você não sabe o que é. E esse "não saber" é extremamente perigoso! Lógico que a gente também não pode achar que tem que saber tudo, mas nós temos que ter uma atenção sobre o fato de que não sabemos, e esse "não saber" precisa ser militante: eu não sei e em uma situação dessas é melhor saber.

Portanto, eu estou ultimamente muito preocupada com isso, porque eu nunca estive numa situação - não estou mais falando da minha doença, que só usei como um exemplo - mas, assim eu nunca tive em uma situação em que observo o quanto o fato de as pessoas não estarem buscando alcançar o "onde a gente está", "que confusão é essa", pode contribuir muito para que as os nossos problemas avancem mais facilmente, porque não temos muita chance de dar um pontapé do tipo "vamos ter que ir pra rua mesmo". Todo mundo hoje está com a situação um pouco assim: "quem sou eu para me meter numa situação dessas?!". 